\title{
Papers
}

\section{Randomised controlled trial of an interactive multimedia decision aid on hormone replacement therapy in primary care}

\author{
Elizabeth Murray, Hilary Davis, Sharon See Tai, Angela Coulter, Alastair Gray, Andy Haines
}

\begin{abstract}
Objective To determine whether a decision aid on hormone replacement therapy influences decision making and health outcomes.

Design Randomised controlled trial.

Setting 26 general practices in the United Kingdom.

Participants 205 women considering hormone replacement therapy.

Intervention Patients' decision aid consisting of an interactive multimedia programme with booklet and printed summary.

Outcome measures Patients' and general practitioners' perceptions of who made the decision, decisional conflict, treatment choice, menopausal symptoms, costs, anxiety, and general health status. Results Both patients and general practitioners found the decision aid acceptable. At three months, mean scores for decisional conflict were significantly lower in the intervention group than in the control group (2.5 $v 2.8$; mean difference $-0.3,95 \%$ confidence interval -0.5 to -0.2 ); this difference was maintained during follow up. A higher proportion of general practitioners perceived that treatment decisions had been made "mainly or only" by the patient in the intervention group than in the control group (55\% v $31 \% ; 24 \%, 8 \%$ to $40 \%$ ). At three months a lower proportion of women in the intervention group than in the control group were undecided about treatment $(14 \%$ v $26 \% ;-12 \%,-23 \%$ to $-0.4 \%)$, and a higher proportion had decided against hormone replacement therapy $(46 \%$ v $32 \% ; 14 \%, 1 \%$ to $28 \%)$; these differences were no longer apparent by nine months. No differences were found between the groups for anxiety, use of health service resources, general health status, or utility. The higher costs of the intervention were largely due to the video disc technology used.

Conclusions An interactive multimedia decision aid in the NHS would be popular with patients, reduce decisional conflict, and let patients play a more active part in decision making without increasing anxiety. The use of web based technology would reduce the cost of the intervention.
\end{abstract}

\begin{tabular}{|c|c|}
\hline Introduction & Department of \\
\hline $\begin{array}{l}\text { Decision aids to assist patients in deciding about health } \\
\text { care have been welcomed as one solution for } \\
\text { improving doctor-patient communication, providing } \\
\text { information for patients, and addressing the shortcom- } \\
\text { ings in much of the information available. }{ }^{1-5} \text { Both }\end{array}$ & $\begin{array}{l}\text { Population } \\
\text { Sciences, Royal Free } \\
\text { and University } \\
\text { College Medical } \\
\text { School, University } \\
\text { College London, } \\
\text { London N19 3UA }\end{array}$ \\
\hline patient outcomes and the rational use of health service & $\begin{array}{l}\text { Elizabeth Murray } \\
\text { senior lecturer }\end{array}$ \\
\hline information. ${ }^{6-9}$ & $\begin{array}{l}\text { Hilary Davis } \\
\text { research fellow }\end{array}$ \\
\hline $\begin{array}{l}\text { Decision aids for patients differ from simple infor- } \\
\text { mation packages. As well as containing information }\end{array}$ & $\begin{array}{l}\text { Sharon See Tai } \\
\text { senior research fellow }\end{array}$ \\
\hline & $\begin{array}{l}\text { Andy Haines } \\
\text { professor }\end{array}$ \\
\hline $\begin{array}{l}\text { patients clarify their own health needs, and they } \\
\text { emphasise that different patients reach different }\end{array}$ & $\begin{array}{l}\text { Picker Institute } \\
\text { Europe, Oxford } \\
\text { OX1 1RX }\end{array}$ \\
\hline $\begin{array}{l}\text { decisions. }{ }^{10} \text { Decision aids aim to promote shared deci- } \\
\text { sion making, }{ }^{11} \text { where the clinician and patient jointly }\end{array}$ & $\begin{array}{l}\text { Angela Coulter } \\
\text { director }\end{array}$ \\
\hline $\begin{array}{l}\text { negotiate and agree on a treatment decision, taking } \\
\text { into account both the probability of a range of clinical } \\
\text { outcomes and the relative weight the patient places on } \\
\text { these outcomes. }\end{array}$ & $\begin{array}{l}\text { Health Economics } \\
\text { Research Centre, } \\
\text { University of } \\
\text { Oxford, Oxford } \\
\text { OX3 7LF }\end{array}$ \\
\hline A recent systematic review of decision aids & $\begin{array}{l}\text { Alastair Gray } \\
\text { director }\end{array}$ \\
\hline $\begin{array}{l}\text { their condition and treatment options. }{ }^{12} \text { They seem to } \\
\text { help with decision making in that "decisional conflict } \\
\text { scores" (a measure of patients' internal perceptions of }\end{array}$ & $\begin{array}{l}\text { Correspondence to: } \\
\text { E Murray } \\
\text { elizabeth.murray@ } \\
\text { pcps.ucl.ac.uk }\end{array}$ \\
\hline ision made) tend to be lower in groups that hav & \\
\hline
\end{tabular}
decision made) tend to be lower in groups that have used a decision aid than in control groups. ${ }^{13}$ There are, however, several unanswered questions, ${ }^{14}$ in particular the impact of decision aids on choice of treatment, satisfaction, health status, and persistence with treatment. Additionally, as most trials have been done in secondary care in the United States, there is little evidence on the use of decision aids in primary care. Few data are also available on clinicians' perceptions of decision aids or their cost effectiveness. We address these questions here and in the accompanying paper on patients with benign prostatic hypertrophy. ${ }^{15}$ The two trials were designed to complement each other by examining qualitatively different decisions in different populations (table 1). In this paper we aimed to determine whether an interactive multimedia decision aid promoted greater patient involvement in decision making and what influence this had on the uptake of hormone replacement therapy, health status, and anxiety. We also 
Table 1 Details of two studies on decision aids

\begin{tabular}{lll} 
Characteristic & Benign prostatic hypertrophy study & Hormone replacement therapy study \\
\hline Decision type & $\begin{array}{c}\text { Irreversible after surgery: "rubicon" } \\
\text { decision }\end{array}$ & Reversible \\
\hline Benefits & Immediate & Immediate and delayed \\
\hline Risks & Immediate & Largely delayed \\
\hline Sex of participants & Men & Women \\
\hline Age of participants & Mostly $\geqslant 60$ & Mostly $\geqslant 50$ \\
\hline Eligible population & Subsection (symptomatic men) & Potentially all menopausal women \\
\hline
\end{tabular}

aimed to determine the acceptability of such a system to patients and general practitioners and the impact on a general practitioner's workload and to undertake an economic analysis.

\section{Participants and methods}

\section{Patient recruitment}

We invited general practitioners in two urban (Oxford and London) areas and one suburban (Harrow) and one semirural (Thame and the Chilterns) area to participate in our study. We asked participating general practitioners to recruit perimenopausal or menopausal women who were facing a decision about whether to start, stop, or continue with hormone replacement therapy. The women needed a sufficient understanding of English to be able to consult without an interpreter. Women were excluded if there was an absolute indication or contraindication to hormone replacement therapy or if they had breast or pelvic cancer, severe visual or hearing impairment, or severe learning difficulties or mental illness. Ethical approval was obtained from local research ethics committees.

\section{Intervention}

The intervention, developed by the Foundation for Informed Medical Decision Making, comprised an interactive multimedia programme, with booklet and printed summary. ${ }^{16}$ Information comprised quantified probabilities of the risks and benefits of hormone replacement therapy taken from systematic reviews and other published data available in 1996 and updated in 1998. Topics discussed were menopausal symptoms, mood changes, skin changes, changes in energy, vaginal dryness, changes in libido, heart disease, osteoporosis, breast cancer, and endometrial cancer. After viewing the programme the patients were given a summary of the information; a copy was also sent to their general practitioners.

As the programme used interactive video disc technology, we imported specialised hardware from the United States. This limited the number of machines available for patients to use. Patients travelled to one of five sites, chosen for ease of access from referring practices, to view the programme in a private room. All the

Table 2 Unit costs in pounds sterling (at 1999 prices) and sources of information used in economic evaluation

\begin{tabular}{lrl} 
Item & Unit cost & Source \\
\hline Generic consultation with doctor & 14.00 & Department of Health \\
\hline Doctor's cost per minute (initial intervention) & 1.62 & Department of Health \\
\hline 3 months' supply of Prempak-C & 15.00 & British National Formulary \\
\hline Specialist referral from doctor & 60.00 & Department of Health TFR2 returns \\
\hline Interactive session* & 216.06 & \\
\hline
\end{tabular}

${ }^{*}$ Total equipment costs $£ 17$ 520. Software cost $\$ 1300$ (£770) per disc; total cost $\$ 6500$ (£3850) plus $£ 400$ for shipping and insurance. Mean cost per patient £216. patients saw the core programme, lasting about one hour; viewing optional sections for further information took up to 30 minutes more.

\section{Randomisation}

Patients randomised to the control group received normal clinical care. Randomisation was performed after obtaining informed consent and baseline data from eligible patients. The randomisation schedule, stratified according to recruitment centre, was generated by computer. Allocations were sealed in opaque numbered envelopes, opened by the study nurse after collection of the baseline data.

\section{Data collection}

We collected data from the patients at baseline and at three and nine months after randomisation. Outcome measures included personal details, decisional conflict scores, patients' and general practitioners' perceptions of who made the decision, treatment preference, persistence with treatment, anxiety (Spielberger state trait anxiety inventory short form) ${ }^{17}$ health status and limitations in physical functioning (SF-36), ${ }^{18}$ health states and valuation of health states (EQ-5D), ${ }^{19}$ and menopausal symptoms (MenQol). ${ }^{20}$ Patients in the intervention group completed a questionnaire immediately after viewing the programme.

After the follow up consultation the general practitioners filled in a questionnaire to determine the time spent on the consultation, their perceptions of who made the treatment decision, and whether the programme had helped or hindered the consultation for patients in the intervention group.

\section{Economic evaluation}

We recorded the resources used by each patient over the trial period. These were the cost of providing the interactive information (video costs, nurse time, and accommodation were shared with the accompanying trial, with $64 \%$ of costs attributed to the present study on the basis of patient numbers), the number and duration of consultations with the general practitioner, the number of referrals to specialists, and the use of hormone replacement therapy and related drugs. The unit costs were attached to resource volumes to obtain a total cost per patient. As the technology we used was superseded by CD Rom, personal computer, and internet technology by the time our trial was completed, we also present some estimates of the costs of an alternative delivery system. Utility was measured with the EQ-5D at baseline and at three and nine months. Valuations of health states were taken from the UK population tariff. ${ }^{21}$ We compared point values, summed values over the trial, and changes from baseline to the end of the trial. We conducted our economic evaluation from the perspective of the healthcare system. All costs are in pounds sterling at 1999 prices. To aid generalisability of the results we obtained unit costs from national sources where possible (table 2).

\section{Sample size}

Evidence has shown that the more information women have about hormone replacement therapy, the greater is the likelihood of their using it. ${ }^{22}$ We therefore hypothesised that more women in the intervention group than in the control group would choose hormone replacement therapy. Allowing for a 30\% dropout rate, 120 women in each arm (84 women 
completing the trial) would give our study an $80 \%$ power of detecting a $15 \%$ point difference in use of hormone replacement therapy (between 8\% and $23 \%)^{23}$ in the two arms at the $5 \%$ significance level. A retrospective calculation showed that the power of our actual sample size to determine the observed difference in decisional conflict score between the two groups at the final assessment was $95 \%$ at the $5 \%$ significance level.

\section{Statistical analysis}

We analysed data for all outcomes for those patients who completed all the assessments. We also performed an intention to treat analysis to allow for those patients who did not complete the study and who were therefore unable to provide data at the nine months' assessment. For that analysis we assumed no change in score on any outcome from the beginning of the study, and we substituted baseline data for the missing data at the final assessment. We present the results for those who completed the nine months' assessment, as the intention to treat analysis did not alter the results.

We compared the change in scores from baseline to final assessment for the MenQol and Spielberger scales between study groups, and we compared decisional conflict scores between the two groups at three and nine months. We present the means and standard deviations for resource use and costs and means and 95\% confidence intervals for differences in resource use and costs by allocation.

\section{Results}

\section{Recruitment}

Overall, 26 general practices agreed to participate; 12 from London and Harrow, 14 from Oxford and Thame and the Chilterns. Between October 1996 and August 1998, 205 women were recruited (figure).

\section{Baseline characteristics}

The intervention and control groups were comparable at baseline (table 3) except for educational achievement, which was higher in the control group. Subsequent analysis showed that educational attainment was not related to use of hormone replacement therapy nor was there an interaction between educational attainment and the intervention.

\section{Reactions to decision aid}

Patients reacted positively to the decision aid (table 4). Women in the intervention group seemed to make a

Table 4 Acceptability of decision aid to patients

\begin{tabular}{lc}
\multicolumn{2}{l}{ No (\%) of patients ( $\mathbf{n = 1 0 1 )}$} \\
\hline Was the video easy to understand? & $84(82)$ \\
\hline Very easy & $17(17)$ \\
\hline Quite easy & 0 \\
\hline Quite difficult & 0 \\
\hline Very difficult & $88(87)$ \\
\hline Effect on understanding of issues around hormone replacement therapy \\
\hline Understand more & $13(13)$ \\
\hline Understand same & 0 \\
\hline Understand less & $56(54)$ \\
\hline Effect on difficulty of decision making & $37(36)$ \\
\hline Easier to decide & $8(8)$ \\
\hline Neither easier nor harder to decide
\end{tabular}

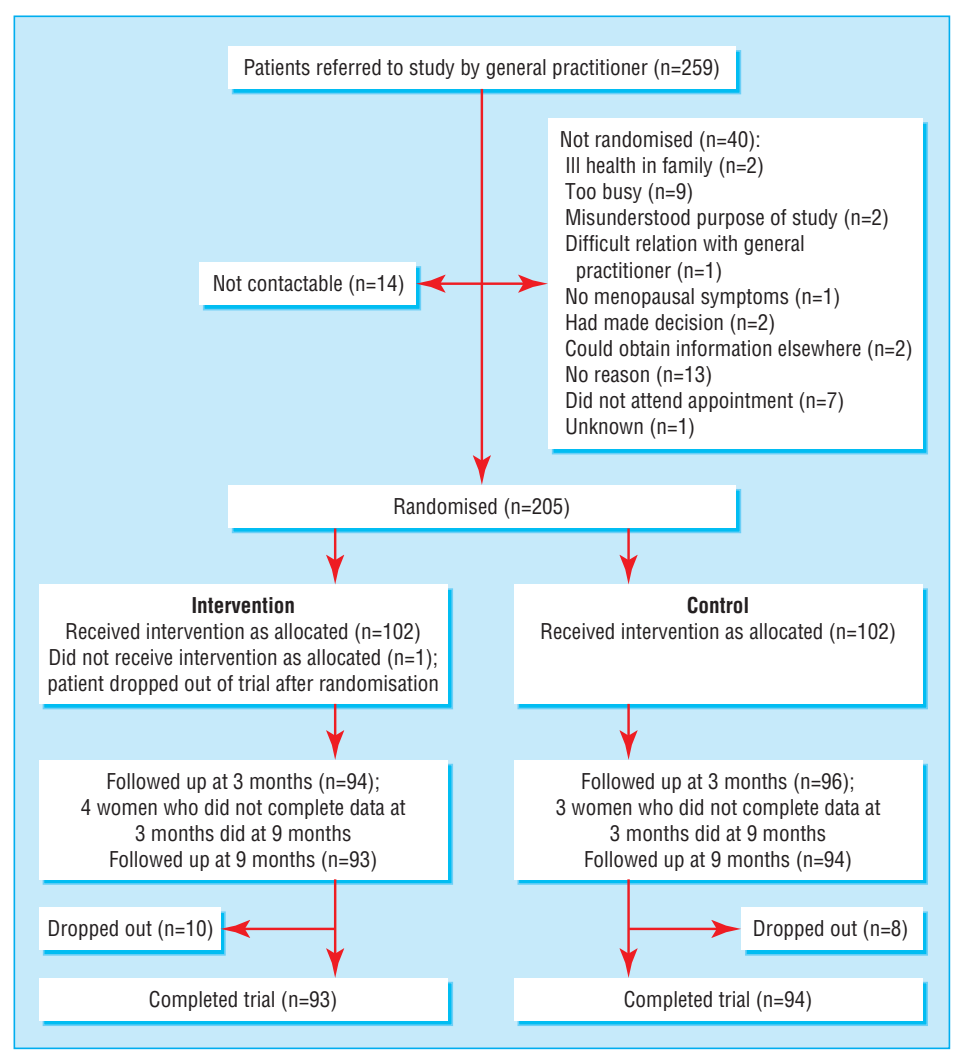

Progress of patients through trial

Table 3 Baseline characteristics of participants. Values are numbers (percentages) of women unless stated otherwise

\begin{tabular}{lcc} 
Characteristic & $\begin{array}{c}\text { Intervention group } \\
(\mathbf{n}=\mathbf{1 0 3})\end{array}$ & $\begin{array}{c}\text { Control group } \\
(\mathbf{n = 1 0 2})\end{array}$ \\
\hline Mean age (years) & 50.75 & 50.11 \\
\hline Ethnicity (white) & $95(92)$ & $93(93)$ \\
\hline Educational attainment: & $40(39)$ & $24(24)$ \\
\hline Up to secondary education & $63(61)$ & $78(77)$ \\
\hline Beyond secondary education & $31(30)$ & $27(27)$ \\
\hline Treatment choice for hormone replacement therapy: & $18(18)$ \\
\hline To take & $21(20)$ & $5(5)$ \\
\hline Not to take & $47(46)$ & $51(51)$ \\
\hline Let doctor decide & & \\
\hline Unsure & $2.71(1.73)$ & $3.02(2.0)$ \\
\hline Mean (SD) MenQol score: & $3.55(1.82)$ & $3.65(1.81)$ \\
\hline Vasomotor & $3.42(1.33)$ & $3.47(1.35)$ \\
\hline Psychosocial & $2.85(2.16)$ & $2.34(1.62)$ \\
\hline Physical & & \\
\hline Sexual & $3.61(0.73)$ & $3.69(0.87)$ \\
\hline Mean (SD) decisional conflict score: & $2.70(0.45)$ & $2.65(0.46)$ \\
\hline Uncertainty & $38.87(12.34)$ & $38.73(13.18)$ \\
\hline Factors contributing to uncertainty & &
\end{tabular}

more definite choice about treatment than those in the control group, with fewer women being "undecided" and more women deciding not to take hormone replacement therapy at three months; by nine months, however, this difference was no longer significant (table 5). This was confirmed by the decisional conflict scores, which were lower in the intervention group than in the control group at three months (table 6); the significant differences persisted at nine months (total score at nine months: mean (SD) scores, intervention group 2.45 (0.56), control group 2.80 (0.61); mean difference 
Table 5 Treatment preferences for hormone replacement therapy at three and nine months' follow up. Values are numbers (percentages) of patients unless stated otherwise

\begin{tabular}{lccc} 
Treatment preference & Intervention group & Control group & \% difference $\mathbf{~} 95 \% \mathbf{C l})$ \\
\hline Three months' follow up*: & & & \\
\hline Therapy & $36(40)$ & $40(42)$ & $-2.1(-16.3$ to 12.1$)$ \\
\hline No therapy & $41(46)$ & $30(32)$ & $14(0.8$ to 27.9$)$ \\
\hline Undecided & $13(14)$ & $25(26)$ & $-11.9(-23.3$ to -0.4$)$ \\
\hline Nine months' follow upt: & & & \\
\hline Therapy & $36(41)$ & $31(36)$ & $5.8(-8.7$ to 20.2$)$ \\
\hline No therapy & $46(53)$ & $44(51)$ & $2.3(-12.5$ to 17.1$)$ \\
\hline Undecided & $5(6)$ & $12(14)$ & $-8.1(-16.8$ to 0.7$)$ \\
\hline
\end{tabular}

Data are missing for some participants.

Confidence intervals are based on $t$ tests assuming unequal variances between study groups. ${ }^{*} \chi^{2}=5.573, \mathrm{df}=2, P=0.06$.

$+\chi^{2}=3.30, d f=2, P=0.2$.

Table 6 Decisional conflict scores at three months. Values are means (SDs) unless stated otherwise

\begin{tabular}{lccc} 
& $\begin{array}{c}\text { Intervention } \\
\text { group }\end{array}$ & Control group & Mean difference $\mathbf{~ ( 9 5 \% ~} \mathbf{~ C l})$ \\
\hline Uncertainty & $3.1(1.0)$ & $3.4(1.1)$ & $-0.3(-0.7 \text { to }-0.04)^{\star}$ \\
\hline Factors contributing to uncertainty & $2.4(0.5)$ & $2.8(0.6)$ & $-0.4(-0.5 \text { to }-0.2)^{\star \star}$ \\
\hline Perceived effective decision making & $2.2(0.6)$ & $2.5(0.7)$ & $-0.3(-0.5 \text { to }-0.2)^{\star \star}$ \\
\hline Total decisional conflict score & $2.5(0.5)$ & $2.8(0.6)$ & $-0.3(-0.5 \text { to }-0.2)^{\star \star}$
\end{tabular}

${ }^{*} \mathrm{P}<0.05$. ${ }^{* * \mathrm{P}}<0.01$

The decisional conflict scale contains three subscales that elicit uncertainty about choosing between alternatives, awareness of modifiable factors contributing to uncertainty, and perceived effectiveness of decision making process. Higher scores indicate increased uncertainty in each subscale. Subscales can be combined to give a total decisional conflict score.

$-0.35,95 \%$ confidence interval for mean difference -0.53 to -0.16$)$. General practitioners perceived the decision to have been made "mainly or only [by the] patient" in a significantly higher proportion of patients in the intervention group than in the control group, although there were no differences in patients' percep-

Table 7 Patients' and general practitioners' perceptions of decision making. Values are numbers (percentages) of patients unless stated otherwise

\begin{tabular}{|c|c|c|c|}
\hline & Intervention group & Control group & $\%$ difference $(95 \% \mathrm{CI})$ \\
\hline General practitioners & $(\mathrm{n}=76)$ & $(n=67)$ & \\
\hline \multicolumn{4}{|c|}{ Who do you think made the treatment decision?: } \\
\hline Mainly or only general practitioner & $1(1.3)$ & $2(3)$ & $-1.7(-6.5$ to 3.1$)$ \\
\hline General practitioner and patient together & $33(43.4)$ & $44(65.7)$ & $-22.3(-38.2$ to -6.3$)$ \\
\hline \multirow[t]{2}{*}{ Mainly or only patient } & $42(55.3)$ & $21(31.3)$ & $24(8.2 \text { to } 39.7)^{*}$ \\
\hline & \multicolumn{3}{|c|}{$\chi^{2}=8.37, d f=2, P=0.015$} \\
\hline Patients & $(n=94)$ & $(n=95)$ & \\
\hline \multicolumn{4}{|c|}{ Who do you think should make the treatment decision?: } \\
\hline Mainly or only general practitioner & $5(5.3)$ & $6(6.3)$ & $-1.0(-7.7$ to 5.7$)$ \\
\hline Patient and general practitioner together & $40(42.6)$ & $36(37.9)$ & $4.7(-9.3$ to 18.6$)$ \\
\hline \multirow[t]{2}{*}{ Mainly or only patient } & $49(52.1)$ & $53(55.8)$ & $-3.7(-17.9$ to 10.5$)$ \\
\hline & \multicolumn{3}{|c|}{$\chi^{2}=0.45, d f=2, P=0.8$} \\
\hline
\end{tabular}

Table 8 Resource use and costs in sterling (at 1999 prices) per patient, by allocation. Values are means (SDs) unless stated otherwise

\begin{tabular}{|c|c|c|c|}
\hline & $\begin{array}{l}\text { Intervention } \\
\quad(\mathrm{n}=85)\end{array}$ & $\begin{array}{l}\text { Control } \\
(\mathrm{n}=84)\end{array}$ & $\begin{array}{l}\text { Mean difference } \\
\quad(95 \% \mathrm{CI})\end{array}$ \\
\hline Cost of video technology & 216.00 & 0 & 216 \\
\hline Duration of initial consultation (minutes) & $13.4(5.9)$ & $13.9(5.8)$ & $-0.5(-2.5$ to 1.6$)$ \\
\hline $\begin{array}{l}\text { No of appointments to see doctor over } \\
9 \text { months }\end{array}$ & $3.4(1.2)$ & $3.6(1.5)$ & $-0.2(-0.6$ to 0.2$)$ \\
\hline Cost of appointments over 9 months & 64.6 (23.6) & $66.5(24.6)$ & $-1.9(-9.2$ to 5.5$)$ \\
\hline No of specialist referrals over 9 months & $0.03(0.17)$ & $0.03(0.18)$ & $0.00(-0.06$ to 0.06$)$ \\
\hline Cost of specialist referrals over 9 months & $1.7(10.1)$ & $1.9(10.6)$ & $-0.19(-3.75$ to 3.37$)$ \\
\hline $\begin{array}{l}\text { Cost of hormone replacement therapy over } \\
9 \text { months }\end{array}$ & $24.3(28.3)$ & $23.0(27.2)$ & $1.3(-7.1$ to 9.7$)$ \\
\hline Total cost & $306.5(42.8)$ & $90.9(39.2)$ & $215.5(203.1 \text { to } 228.0)^{* \star *}$ \\
\hline
\end{tabular}

tions of who should make the decision (table 7). The wording of the question was altered from "who made the treatment decision" (asked in the study on benign prostatic hypertrophy) to "who do you think should make the treatment decision?" as we postulated that many women would not have made a decision about their treatment by the end of the trial.

We found no significant difference between the two groups in the change in anxiety score between baseline and at nine months ( $t$ test, mean change scores: intervention group 0.34, control group 2.49, mean difference $-2.15,-6.45$ to 2.16 ). We also found no significant changes in scores from baseline to final assessment between the two groups in the SF-36 or the EQ-5D or MenQol.

Of 73 subsequent consultations, the general practitioners said that the decision aid helped in 61 (84\%), made no difference in 11 , and hindered one.

\section{Economic analysis}

Table 8 shows the resources used and the costs per patient by allocation group. No significant differences were detected when the cost of the trial technology was excluded. When the cost of the video intervention was included, the cost per patient was $£ 306$ in the intervention group and $£ 91$ in the control group over nine months $(\mathrm{P}<0.001)$.

\section{Discussion}

Our pair of trials are the first randomised controlled trials of interactive multimedia decision aids in a primary care population in the United Kingdom. The decision aid in this paper was acceptable to both the patients and their general practitioners. It enhanced the women's understanding of the effects of hormone replacement therapy and seemed to reduce decisional conflict for the duration of follow up. Lower decisional conflict scores imply less uncertainty about the decision. At three months fewer women in the intervention group than in the control group were undecided about their use of hormone replacement therapy. The general practitioners perceived a higher proportion of patients in the intervention group than in the control group to have "mainly or only" made the decision, although this finding must be interpreted with caution as the doctors were not blinded to the patients' study groups. The intervention made no difference to the rate of uptake of hormone replacement therapy or the use of health service resources in general. The main costs of the intervention were due to the technology used. These findings are compatible with the recent systematic review of decision aids ${ }^{5}$ and provide new information on the acceptability of such decision aids to clinicians and patients in primary care and the impact on costs to the NHS.

\section{Implications for the NHS}

Public demand for improved access to quality sources of information is high and likely to increase. Decision aids have the potential to alter the use of healthcare resources in line with patients' preferences and, through the influence of patient choice on clinicians, may help to promote evidence based practice. ${ }^{24}$ No study has yet examined the effect of decision aids on 


\section{What is already known on this topic}

Patients want more information about their conditions and treatment options, and many want to play an active part in decision making

Decision aids improve patients' knowledge of their conditions and treatment options

\section{What this study adds}

The decision aid was acceptable to both the patients and their general practitioners

Decisional conflict was reduced in the intervention group

Patients who viewed the programme played a more active part in the decision making process and were no more anxious than control patients

Such aids could be introduced throughout the NHS at relatively low cost by using the internet

litigation, although viewing such a programme could be considered evidence of informed consent.

Delivering programmes to standard personal computers through the internet would reduce the cost per session from about $£ 177$ to $£ 5$ (excluding the cost of software). This assumes equipment costs of $£ 1500$ over three years, with a fairly low utilisation rate (two users per weekday) and lower space and staff costs commensurate with a less dedicated technology. Thus this type of interactive decision aid, which provides a realistic and practical solution to the problem of achieving informed patient choice at low cost, could easily be incorporated into multiple access points for information such as those envisaged for NHS Direct Online. Our trial was not designed to determine the extent to which patients would seek out and use a decision aid if they were not referred to it; however the rapid rise in numbers of visitors to health information sites on the internet $^{25}$ confirms previous evidence on the widespread demand by patients for information on health care.

\section{Conclusions}

Evidence shows that further coordinated investment is required in decision aids for patients. This would involve incorporation of information from systematic reviews (where available) into high quality decision aids, particularly addressing decisions where patients' needs are paramount.

We thank Jo Burns for administrative support, the research staff Liz Redfern, Sue Davis, Jean Catterson, and Marjorie Talbot, and the general practitioners. AH is currently based at the London School of Hygiene and Tropical Medicine, London WC1E 7HT

Contributors: AC and AH developed the idea for the study, participated in the design of the trial, and helped write the paper. AG initiated the health economic component of the study, determined the health economic data to be collected, participated in the analysis, and helped write the paper. HD coordinated the project, collected the data, participated in the analysis, and helped write the paper. SST participated in the study design and analysis of the data and helped write the paper. EM, the principal investigator, participated in the research design, coordinated the project, participated in data analysis, and helped write the paper; she will act as guarantor for the paper.

Funding: BUPA Foundation and the King's Fund.

Competing interests: None declared.

1 General Medical Council. Seeking patients'consent: the ethical considerations London: GMC, 1998.

2 Department of Health. Saving lives: our healthier nation. London: Stationery Office, 1999.

3 Jones R, Pearson J, McGregor S, Cawsey AJ, Barret A, Craig N, et al. Randomised trial of personalised computer based information for cancer patients. BMJ 1999;319:1241-7.

4 Meredith C, Symonds P, Webster L, Lamont D, Pyper E, Gillis CR, et al. Information needs of cancer patients in west Scotland: cross sectional survey of patients' views. BMJ 1996;313:724-6.

5 Coulter A, Entwistle V, Gilbert D. Sharing decisions with patients: is the information good enough? BMJ 1999;318:318-22.

6 Legg England S, Evans J. Patients' choices and perceptions after an invitation to participate in treatment decisions. Soc Sci Med 1992;34:1217-25.

7 Kaplan SH, Greenfield S, Ware JEJ. Assessing the effects of physician-patient interactions on the outcomes of chronic disease. Med Care 1989;27:110-27S. [Published erratum appears in Med Care $1989 ; 27: 679$.

8 Flood AB, Wennberg JE, Nease RFJ, Fowler FJJ, Ding J, Hynes LM. The importance of patient preference in the decision to screen for prostate cancer. J Gen Intern Med 1996;11:342-9.

9 Wolf AM, Nasser JF, Schorling JB. The impact of informed consent on patient interest in prostate-specific antigen screening. Arch Intern Med 1996;156:1333-6.

10 Llewellyn TH. Patients' health-care decision making: a framework for descriptive and experimental investigations. Med Decis Making 1995; 15:101-6.

11 Charles C, Gafni A, Whelan T. Shared decision-making in the medical encounter: what does it mean? (Or it takes at least two to tango). Soc Sci Med 1997;44:681-92.

12 O'Connor AM, Rostom A, Fiset V, Tetroe J, Entwistle V, Llewellyn TH, et al. Decision aids for patients facing health treatment or screening decisions: systematic review. BMJ 1999;319:731-4.

13 O'Connor AM. Validation of a decisional conflict scale. Med Decis Making 1995; 15:25-30.

14 Molenaar S, Sprangers MA, Postma-Schuit FC, Rutgers EJ, Noorlander J, Hendriks J, et al. Feasibility and effects of decision aids. Med Decis Makin 2000;20:112-27.

15 Murray E, Davis H, See Tai S, Coulter A, Gray A, Haines A. Randomised controlled trial of an interactive multimedia decision aid on benign prostatic hypertrophy in primary care. BMJ 2001;323:493-6.

16 Foundation for Informed Medical Decision Making. Hormone replacement therapy: a shared decision making program. Clinician's guide. Boston: FIMDM,

17 Marteau TM, Bekker H. The development of a six-item short-form of the state scale of the Spielberger state-trait anxiety inventory (STAI). Br J Clin Psychol 1992;31:301-6.

18 Brazier JE, Harper R, Jones NM, O'Cathain A, Thomas KJ, Usherwood T, et al. Validating the SF-36 health survey questionnaire: new outcome measure for primary care. BMJ 1992;305:160-4.

19 EuroQol Group. EuroQol: a new facility for the measurement of healthrelated quality of life. Health Policy 1990;16:199-208.

20 Hilditch JR, Lewis J, Peter A, van-Maris B, Ross A, Franssen E, et al. A menopause-specific quality of life questionnaire: development and psychometric properties. Maturitas 1996;24:161-75. [Published erratum appears in Maturitas 1996;25:231.]

21 Dolan P, Gudex C, Kind P, Williams A. The time trade-off method: results from a general population study. Health Econ 1996;5:141-54.

22 Isaacs AJ, Britton AR, McPherson K. Utilisation of hormone replacement therapy by women doctors. BMJ 1995;311:1399-401.

23 Townsend J. Hormone replacement therapy: assessment of present use costs, and trends. BrJ Gen Pract 1998;48:955-8.

24 Entwistle VA, Sheldon TA, Sowden A, Watt IS. Evidence-informed patient choice. Practical issues of involving patients in decisions about health care technologies. Int J Technol Assess Health Care 1998;14:212-25.

25 Fox S, Rainie L, Horrigan J, Lenhart A, Spooner A, Burke M, et al. The online health care revolution: how the web helps Americans take better care of themselves. Pew Internet and American Life Project. 1. www.pewinternet.org (accessed 5 January 2001).

(Accepted 6 April 2001) 